\section{The use of maternal and child health services in three population-based cohorts in Southern Brazil, 1982-2004}

\author{
A utilização de serviços de saúde materno-infantil \\ em três coortes de base populacional no Sul do \\ Brasil, 1982-2004
}

\author{
${ }^{1}$ Departamento Materno- \\ Infantil, Universidade \\ Federal do Rio Grande, \\ Rio Grande, Brasil. \\ 2 Programa de Pós-gradu- \\ ação em Epidemiologia \\ Universidade Federal de \\ Pelotas, Pelotas, Brasil. \\ 3 Programa de Pós-gradu- \\ ação em Saúde Coletiva, \\ Universidade do Vale do \\ Rio dos Sinos, São Leopoldo \\ Brasil. \\ 4 Programa de Pós-graduação \\ em Saúde e Comportamento, \\ Universidade Católica de \\ Pelotas, Pelotas, Brasil. \\ Correspondence \\ J. A. Cesar \\ Programa de Pós-graduação \\ em Epidemiologia, \\ Universidade Federal de \\ Pelotas. \\ Rua Marechal Deodoro 1160 , \\ sala 313, Pelotas, RS \\ 96020-220, Brasil. \\ jacesar@terra.com.br
}

\begin{abstract}
This study aimed to describe indicators of health care assistance during antenatal care, delivery and in the first year of life in Pelotas, Rio Grande do Sul State, Brazil. In 1982, 1993, and 2004, all hospital newborns from the urban area of Pelotas were enrolled in a cohort study. In this period, the number of pregnant women that did not attend antenatal care fell from $4.9 \%$ to $1.9 \%$; the mean number of appointments increased from 6.7 to 8.1; and the number of women who began antenatal care in the third trimester of pregnancy decreased from $14.8 \%$ to $7 \%$; caesarean sections increased from $27.7 \%$ to $45.2 \%$ and the proportion of deliveries assisted by physicians increased from $61.2 \%$ to $89.2 \%$. Improvements in immunization rates during the first year of life mainly occurred between 1982 and 1993, while the number of preventive medical appointments improved among those born in 2004. This increase in coverage was greater for low-income mothers and children, which may reflect the implementation of universal coverage in Brazil; however, coverage levels in 1982 were already high for wealthy mothers and children, reducing the scope for further gains.
\end{abstract}

Maternal and Child Health; Health Services; Cohort Studies

\author{
Juraci A. Cesar 1,2 \\ Alicia Matijasevich 2 \\ Iná S. Santos 2 \\ Aluísio J. D. Barros 2 \\ Juvenal S. Dias-da-Costa 2,3 \\ Fernando C. Barros 4 \\ Cesar G. Victora ${ }^{2}$
}

\section{Introduction}

The medical care provided during pregnancy and delivery has an enormous potential to reduce infant and maternal mortality. At least half of all infant deaths and most maternal deaths are due to events related to pregnancy and delivery 1,2 .

The supply of antenatal and delivery care in Brazil has improved in recent years 1 . According to data from the Information System on Live Births (SINASC; http://www.datasus.gov.br, accessed on $06 / \mathrm{Sep} / 2007$ ), only $2.6 \%$ of Brazilian mothers went through pregnancy without any antenatal care appointments in 2004. This proportion was $3.7 \%$ in the country's Northeast Region, compared with $1.2 \%$ in the South. In the mid 1990's, this was true for $15 \%$ of all Brazilian mothers, ranging from $4 \%$ in the South to $25 \%$ in the Northeast 3 . This scenario is further complicated by the fact that many pregnant women do not receive the basic routine tests, and by the preference given to tests with little impact on infant welfare - e.g., ultrasonography - in detriment of venereal disease research laboratory (VDRL) testing ${ }^{4}$. This hinders the early identification and proper management of a range of diseases, which contribute towards the high levels of infant and maternal morbidity and mortality seen in the entire country, especially in poorer areas 1 . To make matters worse, the care supplied is often at odds with the mother's needs. This is frequently the case for c-sections, 
which are more frequently performed on mothers at lower risk 5 .

Two important elements of health service utilization are vaccine coverage and the frequency of medical appointments during the child's first year. Service utilization provides information on both service accessibility and on the expected morbidity patterns within a population.

Newborn cohorts allow for these aspects to be studied in greater depth. The present article reports on trends in basic indicators related to pregnancy, delivery, and infant care, and on how these indicators differed according to family income, gestational risk, and mode of financing between 1982, 1993, and 2004, in the city of Pelotas, Rio Grande do Sul State, Southern Brazil.

\section{Methods}

The cohort studies were conducted in the city of Pelotas, Southern Brazil, a city of about 340,000 inhabitants located in the southern half of the State of Rio Grande do Sul, the poorest region in this state. The public healthcare network comprises 53 primary healthcare facilities, five hospitals with 1,100 beds available through the Unified National Health System (SUS), and five medical specialty outpatient facilities. Infant mortality has remained stable at around 20/1,000 in recent years, which is higher than the state average of about 15/1,000 6 .

Between 1 January and 31 December of 1982, 1993, and 2004, all mothers giving birth to living babies in any of the city's maternity wards were interviewed as part of the perinatal component of the cohort studies. All newborns residing within the urban area of Pelotas or the Jardim América neighborhood, which since 1982 has belonged to the municipality of Capão do Leão, but which is contiguous with the urban area of Pelotas, were included in these studies. Children from the three cohorts were visited at home upon after turning one. Data on health service utilization in the first year of life were collected during this 12-month follow-up for the 1982 study, and at 6 and 12 months for the 1993 and 2004 studies. Detailed descriptions of the methods employed in these studies are provided elsewhere 7

Although most variables included in the present analysis are self-explanatory, certain variables require further clarification:

1) Antenatal care: we considered as having received antenatal care any pregnant woman who had at least one pregnancy-related appointment with a physician or nurse, be it due to pregnancyrelated health problems or for routine follow-up only;
2) Month of onset of antenatal care: gestational age at which the mother had her first pregnancyrelated medical appointment. This was collected as a discrete variable. Based on this variable, we created a dichotomous variable in which mothers were classified as those who had begun antenatal care between the first and fifth months of pregnancy, and those who had begun care during the sixth, seventh, and eighth months;

3) Number of appointments: total appointments from the beginning of pregnancy to the immediate pre-delivery period. Collected as a discrete variable;

4) Mode of delivery: the mother was asked whether the child was delivered by the vaginal route or by caesarian section. If the child was delivered vaginally, the mother was asked whether or not a forceps was used;

5) Person responsible for delivery: refers to the person providing care to the mother at the time of birth. This variable included the following categories: delivery performed by physician, student, nurse, traditional birth attendant, or other; 6) Family income: total amount, in minimum wages, earned by all persons living in the household in the month preceding the interview;

7) Mode of financing: refers to the mode of financing of delivery. This variable was classified into four categories: (a) public-pregnant women seen entirely through the SUS public system and therefore free of charge (in 1982, this category included users of the Instituto Nacional de Assistência Médica da Previdência Social, or INAMPS, which preceded SUS, but which did not offer universal coverage); (b) public + private - refers to pregnant women that, in addition to using the public healthcare system, also had to pay an additional sum to a hospital or physician; (c) private - hospital and physician paid using private money; and (d) health insurance - both hospital and physician costs were paid for in their entirety by private health insurance. In 1982, there was also an "indigent" category, which corresponded to mothers not covered by any type of health insurance, and who entered the healthcare system in this condition. In the following cohorts, this category ceased to exist, due to the implementation of SUS following the establishment of the 1988 Constitution;

8) Gestational risk: calculated based on the score proposed by Chamberlain et al. ${ }^{8}$, and adapted for use in this study 9 , this score classifies risk according to demographic characteristics (age 20-29 years: 0 points; $30-34$ years: 1 point; and under 20 or over 35 years: 2 points); parity (12 children: 0 points; 0 or 3 children: 1 point; 4 or more children: 2 points); history of abortion, neonatal death, and stillbirth (4 points each); low 
birthweight (2 points); family income (more than 6 monthly minimum wages: 0 points; $3.1-6$ minimum wages: 1 point; under 3 minimum wages: 2 points); previous morbidity (history of diabetes: 4 points); nutritional status (mother's height < 150cm: 1 point); lifestyle (smoking: 1 point); and marital status (without partner: 2 points). Mothers with scores between 0 and 2 were considered as at low gestational risk; between 3 and 7 points, intermediate risk; and equal to or greater than 8 points, high risk.

Outcomes evaluated in the first year of life included number of programmed appointments and vaccine coverage. Programmed or preventive appointments were defined as those in which the child was taken to the health facility for growth monitoring or vaccination purposes. The vaccination scheme in use differed between the three cohorts. In 1982, at the end of the first year of life, all children should have received three doses of the Sabin and triple (diphtheria, tetanus, and pertussis) vaccines and one dose of the anti-measles vaccine. In 1993, BCG at birth was added to this scheme. In 2004, the triple vaccine was replaced by the tetravalent (diphtheria, tetanus, pertussis, and haemophilus B), while the anti-measles vaccine, which was previously given at age 9 months, was shifted to after the child's first year. Anti-measles coverage was not evaluated in 2004 .

Data analysis consisted of association tests between dependent variables (presence of antenatal care, mean number of appointments, gestational age at first antenatal care appointment, delivery by c-section, and delivery by a physician) and independent variables (family income, gestational risk, and mode of financing). The magnitude of these differences was assessed using the chi-squared test or analysis of variance 10 . All analyses were carried out using the Stata statistical package, version 9.2 (Stata Corp., College Station, USA).
The study protocol was approved by the Medical Ethics Committee of the Federal University of Pelotas. In 1982 and 1993, verbal consent was obtained from mothers for participation in the study. In 2004, written consent was also requested.

\section{Results}

The cohorts comprised 6,011 births in 1982, 5,304 in 1993, and 4,287 in 2004, all residing in the urban area of Pelotas and born in any of the city's five hospitals.

The proportion of mothers that did not receive antenatal care fell by about $60 \%$ in the 22 year period, from $4.9 \%$ in 1982 to $1.9 \%$ in 2004 ( $\chi^{2}$ for linear trend $\mathrm{p}<0.001$ ) (Table 1$)$. In this same period, the mean number of appointments increased by 1.4 , from 6.7 to 8.1 appointments per mother. The percentage of mothers that began antenatal care after the fifth month of pregnancy fell to less than half its original value, from $14.8 \%$ to $7.0 \%$ ( $\chi^{2}$ for linear trend $\mathrm{p}<0.001$ ).

Table 2 shows that the percentage of women without antenatal care fell across all income strata, but especially among poorer women. Among women with family income of up to 1 monthly minimum wage, there was an almost four-fold reduction, from $13 \%$ to $3.3 \%$ ( $\chi^{2}$ for linear trend $p$ $<0.001)$. In the income group immediately above - earning between 1.1 and 3 times the minimum wage - the same reduction was almost three-fold, from $3.9 \%$ to $1.4 \%$ ( $\chi^{2}$ for linear trend $p=0.001$ ). The number of appointments also increased across all income groups, and again especially among the poor. In 2004, poorer women had on average two more appointments than in 1982, whereas for those with an income of more than six times the minimum wage this number increased by only one appointment. The percent-

Indicators of antenatal care utilization. Pelotas, Southern Brazil, 1982, 1993, and 2004.

\begin{tabular}{|c|c|c|c|c|}
\hline Indicator & 1982 & 1993 & 2004 & p \\
\hline Women without antenatal care (\%) & 4.9 & 4.8 & 1.9 & $<0.001 * \star$ \\
\hline Mean antenatal care appointments (\%) * & 6.7 & 7.6 & 8.1 & $<0.001 * \star \star$ \\
\hline First appointment after fifth month of pregnancy (\%) & 14.8 & 9.0 & 7.0 & $<0.001 * \star$ \\
\hline Total $(n)$ & 6,011 & 5,304 & 4,287 & - \\
\hline
\end{tabular}

* Including mothers with zero appointments;

${ }^{\star *} \chi^{2}$ test of trend;

$\star \star \star$ Test of trend (ANOVA). 
Antenatal care utilization according to family income, maternal risk, and means of financing. Pelotas, Southern Brazil, 1982,1993, and 2004.

\begin{tabular}{|c|c|c|c|c|c|c|c|c|c|}
\hline \multirow[t]{2}{*}{ Variable } & \multicolumn{3}{|c|}{$\begin{array}{l}\text { No antenatal } \\
\text { care }(\%)\end{array}$} & \multicolumn{3}{|c|}{$\begin{array}{l}\text { Mean number of } \\
\text { appointments (\%) }\end{array}$} & \multicolumn{3}{|c|}{$\begin{array}{l}\text { First appointment after } \\
\text { fifth month of pregnancy (\%) }\end{array}$} \\
\hline & 1982 & 1993 & 2004 & 1982 & 1993 & 2004 & 1982 & 1993 & 2004 \\
\hline \multicolumn{10}{|c|}{ Family income (as a multiple of the } \\
\hline \multicolumn{10}{|c|}{ monthly minimum wage) } \\
\hline$\leq 1$ & 13.0 & 9.9 & 3.3 & 4.9 & 6.0 & 6.8 & 26.0 & 15.8 & 12.4 \\
\hline $1.1-3$ & 3.9 & 4.8 & 1.4 & 6.4 & 7.2 & 8.2 & 16.6 & 9.7 & 5.9 \\
\hline $3.1-6$ & 1.7 & 2.9 & 0.4 & 7.8 & 8.2 & 9.7 & 7.3 & 6.6 & 2.6 \\
\hline 6.1-10 & 0.3 & 3.0 & 1.8 & 8.4 & 9.5 & 10.4 & 4.1 & 3.5 & 1.8 \\
\hline$>10$ & 0.0 & 0.3 & 0.0 & 9.4 & 10.2 & 10.6 & 2.4 & 2.8 & 1.8 \\
\hline \multicolumn{10}{|l|}{ Risk level } \\
\hline High & 7.1 & 5.7 & 1.7 & 6.1 & 7.1 & 7.2 & 17.3 & 13.0 & 9.4 \\
\hline Intermediate & 5.6 & 3.5 & 1.9 & 6.4 & 7.5 & 8.1 & 17.3 & 9.6 & 6.8 \\
\hline Low & 1.7 & 1.2 & 0.0 & 7.7 & 8.9 & 9.5 & 7.5 & 4.8 & 4.0 \\
\hline \multicolumn{10}{|l|}{ Means of financing } \\
\hline Public & 3.0 & 5.7 & 2.2 & 6.5 & 7.1 & 7.5 & 16.8 & 10.6 & 8.3 \\
\hline Public + private & - & 0.6 & 0.0 & - & 9.6 & 11.7 & - & 1.1 & 0.0 \\
\hline Private & 0.0 & 0.0 & 0.0 & 9.0 & 10.3 & 10.5 & 2.6 & 1.2 & 0.5 \\
\hline Health insurance & 2.2 & 0.2 & 0.5 & 9.0 & 10.6 & 10.7 & 3.1 & 2.2 & 1.5 \\
\hline Indigent & 45.9 & * & * & 2.5 & * & * & 20.5 & * & * \\
\hline
\end{tabular}

* Data not available due to the inexistence of this category after the implementation of the Unified National Health System (SUS).

age of women who began antenatal care after the fifth month of pregnancy fell drastically in the 22 year period in all income groups. The greatest reductions occurred among women in the intermediate income groups (earning between 1.1 and 3.0 times the minimum wage and between 3.1 and 6.0).

Regarding gestational risk, a quarter of mothers in 1982 and 1993, and 18\% in 2004 were classified as low gestational risk. Prevalence of medium gestational risk was $63 \%$ in $1982,61 \%$ in 1993 , and $68 \%$ in 2004 . Finally, prevalence of high gestational risk was 13\% in 1982 and 1993, and $14 \%$ in 2004.

Antenatal care in the three cohorts was also evaluated in relation to gestational risk (Table 2). Between 1982 and 2004, the probability of not receiving antenatal care fell by 4.2 times (from $7.1 \%$ to $1.7 \%$ ) among high risk mothers ( $\chi^{2}$ for linear trend $\mathrm{p}<0.001)$ and by 2.9 times $(5.6 \%$ to $1.9 \%)$ among the intermediate risk category ( $\chi^{2}$ for linear trend $\mathrm{p}<0.001$ ). All low-risk mothers had at least one antenatal care appointment in 2004. The mean number of appointments also increased in the period across all gestational risk groups, but especially among intermediate and low-risk pregnancies (ANOVA test trend $\mathrm{p}<0.001$ ). These women had on average one more appointment in 2004 than in 1982. Regarding gestational age at the beginning of antenatal care, the percentage of women that began care after the fifth month fell to half the original level in these 22 years, regardless of gestational risk ( $\chi^{2}$ for linear trend $\mathrm{p}$ $<0.001)$. However, certain differences exist. In 2004 , whereas only $4 \%$ of women in the lower risk category began antenatal care after the fifth month, this proportion was $9.4 \%$ among highrisk mothers, or 2.3 times greater $\left(\chi^{2} \mathrm{p}<0.001\right)$.

With respect to the means of financing, Table 2 shows that the prevalence of mothers in the public sector that did not have any appointments fell from $3 \%$ in 1982 to $2.2 \%$ in $2004\left(\chi^{2} \mathrm{p}<0.001\right)$. The "indigent" category, present in 1982, was later incorporated into the public sector following the universalization of health care which took place in 1988. The mean number of appointments in the public sector increased in the period (form 6.5 in 1982 to 7.5 in 2004) (ANOVA test trend p < 0.001 ), but remained lower than that registered in the private and health insurance sectors.

Table 3 shows that between 1982 and 2004, there was a $63 \%$ increase in the incidence of csections in the city of Pelotas, which rose from $27.7 \%$ to $45.2 \%$ ( $\chi^{2}$ for linear trend $p<0.001$ ). In 
Delivery care indicators. Pelotas, Southern Brazil, 1982, 1993, and 2004.

\begin{tabular}{|c|c|c|c|c|}
\hline Indicator & 1982 & 1993 & 2004 & $p$ * \\
\hline c-sections (\%) & 27.7 & 30.5 & 45.2 & $<0.001$ \\
\hline Deliveries assisted by a physician (\%) & 61.2 & 88.3 & 89.2 & $<0.001$ \\
\hline Deliveries assisted by a student (\%) & 21.4 & 6.9 & 8.7 & $<0.001$ \\
\hline Deliveries assisted by a traditional birth attendant (\%) & 17.0 & 3.7 & 0.6 & $<0.001$ \\
\hline Total (n) & 6,011 & 5,304 & 4,287 & - \\
\hline
\end{tabular}

* $\chi^{2}$ test of trend.

this same period, the number of deliveries performed by physicians increased by $46 \%$, from $61.2 \%$ to $89.2 \%$ ( $\chi^{2}$ for linear trend $\mathrm{p}<0.001$ ). Unlike 1982, when one out of every five deliveries was carried out by students, in 2004, only one out of eleven was assisted only by a student. An even greater reduction occurred in deliveries assisted by traditional birth attendants, which accounted for $17 \%$ of deliveries in 1982 and only $0.6 \%$ in 2004 ( $\chi^{2}$ for linear trend $\mathrm{p}<0.001$ ).

Table 4 shows the variation in the occurrence of c-sections and physician deliveries according to family income, gestational risk, and means of financing. In these 22 years, the rate of c-sections increased in all income strata, but especially among poorer women. In the lowest income group, incidence increased 2.1-fold between 1982 (16.9\%) and 2004 (36.4\%). Relative increases were less marked in the remaining income categories, partly because levels in 1982 were already high. The occurrence of c-sections also increased across all risk categories $-62.4 \%$ among low-risk mothers $\left(\chi^{2}\right.$ for linear trend $\mathrm{p}<0.001), 71.8 \%$ among the intermediate group $\left(\chi^{2}\right.$ for linear trend $\mathrm{p}<0.001$ ), and $58.2 \%$ among high-risk mothers ( $\chi^{2}$ for linear trend $\mathrm{p}<0.001$ ). Among mothers seen in the public sector, incidence of c-sections increased by $46 \%$, from $24.7 \%$ in 1982 to $36.1 \%$ in 2004 . Figure 1 shows the occurrence of c-sections in the extreme categories of family income and means of financing. The "public + private" category was not defined in 1982.

The proportion of deliveries carried out by physicians increased in all income groups, especially among poorer mothers. For mothers earning up to 1 minimum wage, this increase was $85.6 \%$ ( $\chi^{2}$ for linear trend $\mathrm{p}<0.001$ ), compared with a little over $20 \%$ among mothers earning more than 6 minimum wages $\left(\chi^{2}\right.$ for linear trend $\mathrm{p}<0.001$ ), among which levels in 1982 were already high. Among mothers with intermediate or high gestational risk, there was an increase of about $55 \%$ in physician-assisted deliveries $\left(\chi^{2}\right.$ for linear trend $\mathrm{p}<0.001)$, whereas among low-risk mothers this increase was $30 \%$ ( $\chi^{2}$ for linear trend $\mathrm{p}<0.001$ ). Finally, physicians also performed a greater proportion of deliveries across all modes of financing, especially among the public sector - from $57.3 \%$ in 1982 to $86.7 \%$ in 2004 ( $\chi^{2}$ for linear trend $\mathrm{p}<0.001$ ) (Table 4).

Tables 5 and 6 show vaccine coverage in the first year of life. Between 1982 and 1993, there was a substantial increase in coverage rates for the Sabin and triple vaccines $\left(\chi^{2}\right.$ for linear trend $\mathrm{p}<0.001)$. Anti-measles coverage did not change between 1982 and $1993\left(\chi^{2} \mathrm{p}=0.8\right)$. BCG was not evaluated in 1982, since at that time it was offered only at age 7 years (Table 5).

Children from higher income families showed greater vaccine coverage (Table 6), but the greatest increases in coverage between 1982 and 1993 were registered among the poorest population. Coverage for Sabin and triple in 2004 were equal to, or even lower than, those of 1993 (Table 6).

Table 7 shows an increase in preventive (or programmed) appointments across all income strata. This was not the case for curative (or nonprogrammed) appointments. Considering both preventive and curative appointments in the period, there was a statistically significant increase across all family income categories $\left(\chi^{2}\right.$ for linear trend $\mathrm{p}<0.001$ for income categories $\leq 1.0,1.1$ 3.0 and 3.1-6.0 times the minimum wage; $\mathrm{p}=$ 0.003 for $6.1-10.0$ times the minimum wage, and $\mathrm{p}=0.0003$ for the $>10.0$ times the minimum wage category).

\section{Discussion}

Between 1982 and 2004, there was a substantial improvement in the supply of antenatal care in Pelotas. Virtually all pregnant women received 
Table 4

Delivery care according to family income, maternal risk, and mode of financing. Pelotas, Southern Brazil, 1982, 1993 , and 2004.

\begin{tabular}{|c|c|c|c|c|c|c|}
\hline \multirow[t]{2}{*}{ Variable } & \multicolumn{3}{|c|}{ c-sections (\%) } & \multicolumn{3}{|c|}{ Deliveries assisted by physician (\%) } \\
\hline & 1982 & 1993 & 2004 & 1982 & 1993 & 2004 \\
\hline \multicolumn{7}{|c|}{ Family income (as a multiple of the } \\
\hline \multicolumn{7}{|c|}{ monthly minimum wage) } \\
\hline$\leq 1$ & 16.9 & 23.4 & 36.4 & 46.4 & 84.0 & 86.1 \\
\hline $1.1-3$ & 25.3 & 25.1 & 42.3 & 58.4 & 87.6 & 88.8 \\
\hline $3.1-6$ & 36.2 & 33.3 & 55.0 & 69.4 & 88.4 & 92.2 \\
\hline $6.1-10$ & 41.3 & 45.1 & 74.7 & 80.9 & 94.9 & 97.6 \\
\hline$>10$ & 46.7 & 55.7 & 79.1 & 93.2 & 95.9 & 98.2 \\
\hline \multicolumn{7}{|l|}{ Risk level } \\
\hline High & 26.1 & 28.2 & 41.3 & 56.9 & 87.9 & 89.0 \\
\hline Intermediate & 25.9 & 29.1 & 44.5 & 58.5 & 87.7 & 89.3 \\
\hline Low & 33.0 & 37.2 & 53.6 & 70.3 & 91.1 & 91.4 \\
\hline \multicolumn{7}{|l|}{ Means of financing } \\
\hline Public & 24.7 & 24.4 & 36.1 & 57.3 & 86.2 & 86.7 \\
\hline Public + private & - & 66.5 & 100.0 & - & 98.9 & 100.0 \\
\hline Private & 53.1 & 63.3 & 87.9 & 97.6 & 99.6 & 100.0 \\
\hline Health insurance & 44.6 & 57.5 & 83.2 & 92.7 & 98.0 & 99.8 \\
\hline Indigent & 11.5 & $\star$ & * & 11.5 & $\star$ & $\star$ \\
\hline
\end{tabular}

* Data not available due to the inexistence of this category after the implementation of the Unified National Health System (SUS).

\section{Figure 1}

Frequency of c-sections according to family income and means of financing. Pelotas, Southern Brazil, 1982, 1993 , and 2004.

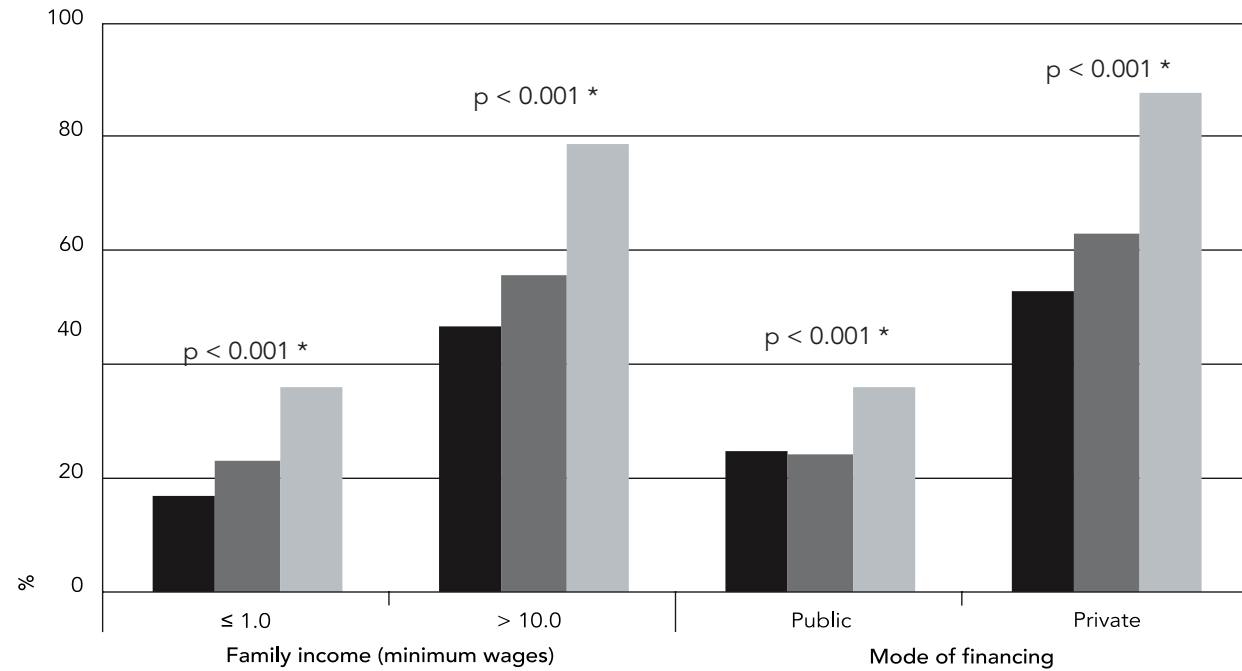


some form of antenatal care. The mean number of appointments increased, and the percentage of pregnant women who were late in beginning antenatal care decreased. For infants, there was an improvement in vaccine coverage between 1982 and 1993, as well as an increase in the number of medical appointments, especially for preventive reasons. These improvements, revealed by the differences between the three cohorts, were generally more marked among poorer mothers and children. Care for women at higher gestational risk increased, but inequalities still remain. The frequency of deliveries assisted by physicians and of c-sections also increased significantly in the period.

Certain methodological differences between the cohorts must be highlighted. There was some difficulty regarding the "means of financing" variable between cohorts due to differences in the categories used for classification, especially
Table 5

Coverage of Sabin, triple, and anti-measles vaccines during first year of life. Pelotas, Southern Brazil, 1982, 1993, and 2004.

\begin{tabular}{lccc}
\hline Indicator & 1982 & 1993 & $\mathbf{2 0 0 4}$ \\
\hline Sabin [3 doses] (\%) & 87.8 & 95.9 & 89.7 \\
Triple * [3 doses] (\%) & 82.8 & 89.7 & 89.8 \\
BCG ** (\%) & - & 97.0 & 93.8 \\
Anti-measles *** (\%) & 87.3 & 87.0 & - \\
Total (n) & 1,457 & 1,364 & 3,907 \\
\hline
\end{tabular}

* In 2004, this vaccine was replaced by the tetravalent (diphtheria, tetanus, pertussis, and haemophilus B);

** Not given at birth in 1982;

$\star \star \star$ Not evaluated in 2004.

Table 6

Coverage of Sabin, triple, and anti-measles vaccines during first year of life according to family income. Pelotas, Southern Brazil, 1982,1993 , and 2004.

\begin{tabular}{|c|c|c|c|c|c|c|c|c|c|}
\hline \multirow{2}{*}{$\begin{array}{l}\text { Family income (as a multiple of the } \\
\text { monthly minimum wage) }\end{array}$} & \multicolumn{3}{|c|}{ Sabin (\%) } & \multicolumn{3}{|c|}{ Triple (\%) } & \multicolumn{3}{|c|}{ Measles (\%) } \\
\hline & 1982 & 1993 & 2004 & 1982 & 1993 & 2004 & 1982 & 1993 & 2004 \\
\hline$\leq 1$ & 78.7 & 94.7 & 84.1 & 71.1 & 84.9 & 84.9 & 79.9 & 84.0 & - \\
\hline $1.1-3$ & 87.4 & 95.9 & 91.1 & 82.1 & 89.2 & 91.1 & 87.1 & 85.3 & - \\
\hline $3.1-6$ & 93.5 & 95.8 & 91.7 & 88.6 & 91.0 & 91.5 & 90.7 & 87.9 & - \\
\hline $6.1-10$ & 95.8 & 97.4 & 89.4 & 93.9 & 96.0 & 89.4 & 95.8 & 97.4 & - \\
\hline$>10$ & 97.1 & 97.3 & 91.0 & 96.0 & 93.9 & 91.0 & 94.9 & 89.8 & - \\
\hline
\end{tabular}

Table 7

Mean number of appointments per year in children aged 12 months according to family income. Pelotas, Southern Brazil, 1982,1993 , and 2004.

\begin{tabular}{|c|c|c|c|c|c|c|c|c|c|}
\hline \multirow[t]{3}{*}{ Indicator } & \multicolumn{9}{|c|}{ Mean appointments in last 12 months } \\
\hline & \multicolumn{3}{|c|}{ Preventive } & \multicolumn{3}{|c|}{ Only curative } & \multicolumn{3}{|c|}{ Total } \\
\hline & 1982 & 1993 & 2004 & 1982 & 1993 & 2004 & 1982 & 1993 & 2004 \\
\hline \multirow{2}{*}{\multicolumn{10}{|c|}{$\begin{array}{l}\text { Family income (as a multiple of the } \\
\text { monthly minimum wage) }\end{array}$}} \\
\hline & & & & & & & & & \\
\hline$\leq 1$ & 7.5 & 5.9 & 9.3 & 3.6 & 3.0 & 3.1 & 11.2 & 9.0 & 12.5 \\
\hline $1.1-3$ & 8.6 & 7.1 & 10.2 & 3.7 & 3.2 & 3.4 & 12.2 & 10.3 & 13.6 \\
\hline $3.1-6$ & 9.9 & 7.6 & 10.8 & 3.1 & 3.5 & 3.1 & 13.0 & 11.2 & 13.9 \\
\hline $6.1-10$ & 10.1 & 8.6 & 11.0 & 2.3 & 3.1 & 2.6 & 12.5 & 11.8 & 13.6 \\
\hline$>10$ & 10.4 & 9.1 & 11.3 & 2.6 & 3.0 & 3.0 & 13.1 & 12.1 & 14.3 \\
\hline All children & 8.9 & 7.3 & 10.3 & 3.4 & 3.2 & 3.2 & 12.3 & 10.5 & 13.5 \\
\hline$\chi^{2}$ test of trend & $<0.001$ & $<0.001$ & $<0.001$ & $<0.010$ & 0.200 & 0.008 & 0.010 & $<0.001$ & $<0.001$ \\
\hline
\end{tabular}


with regard to 1982 . With the implementation of the SUS public system, the "indigent" category - in which risk was highest - was eliminated. According to the new classification, mothers hospitalized through the Brazilian Institute of Social Security (INSS) and indigents were grouped into the "public" category, which includes all deliveries financed by SUS.

It is also worth mentioning that, although several diseases such as systemic arterial hypertension or urinary tract infections increase pregnancy risk, mothers with these diseases were not considered to be at risk because the classification used, based on Chamberlain et al. 8, only takes into account diabetes mellitus.

In Pelotas, only one in every 50 mothers did not have an antenatal care appointment during pregnancy; data from the 1996 National Survey of Demography and Health (1996 PNDS) show that this is true for one in every four mothers in Brazil's Northeast Region, and for one in every eight in the country as a whole 1 . In the neighboring city of Rio Grande, Rio Grande do Sul 6\% of mothers failed to receive antenatal care in 2004, whereas in the city of São Paulo, Brazil between 1984/85 and $1995 / 96$, about $7 \%$ of pregnant women did not receive antenatal care 11,12. Such broad coverage in Pelotas is likely due to the city's abundant primary healthcare network, with one primary healthcare unit for every 6 thousand inhabitants, and with $75 \%$ of the city's households located less than $1 \mathrm{~km}$ from the nearest facility 13 .

The early onset of antenatal care allows for the early detection and adequate management of maternal diseases - e.g. syphilis, diabetes, urinary infections, arterial hypertension, and HIV/AIDS - and risk factors - e.g. smoking and alcoholism. It also allows for the implementation of preventive measures such as immunization against neonatal tetanus. Such measures contribute towards reducing the number of deaths due to preterm birth, low birth weight, respiratory distress syndrome, and neonatal tetanus, among others. In 1982 14, one out of every seven women in Pelotas began antenatal care after the fifth month of pregnancy, whereas in 2004 this occurred for only $7 \%$ of women. In Rio Grande, only $4 \%$ of women began antenatal care appointments after the fifth month of pregnancy 11. The 1996 PNDS showed that twothirds of Brazilian women began antenatal care during the first trimester, ranging from $80 \%$ in the South to roughly half in the Northeast ${ }^{3}$. In Rio Grande, as well as in the city of São Paulo, roughly two-thirds of pregnant women began antenatal care in the first trimester 11,12.

A re-analysis of the Pelotas data to make it compatible with that of the PNDS showed that in $1982,61.5 \%$ of women began antenatal care in the first trimester, with this percentage increasing to $72.3 \%$ in 1993 and $72.9 \%$ in 2004 .

The proportion of women in Pelotas who began antenatal care in the first trimester in 1982 was very similar to the Brazilian average according to the 1996 PNDS 3 . The greatest advancement occurred between the first and second cohorts, and the level remained stable thereafter. A reason for concern is the fact that one third of women still do not begin antenatal care at the most appropriate time. This is due to the fact that the local healthcare system does not actively search for mothers, which could be achieved by means of community agents, within their area of coverage. Although these agents do not cover the city's entire population, they act in the poorest areas of the city, in which there are greater proportions of women at higher risk of complications during pregnancy and delivery.

It is also worth noting the expressive number of women classified as "indigent" in the 1982 cohort 13 . These women, then at the margin of healthcare services and served mainly by the local Catholic hospital "as a favor" or "for charity," appeared in the 1993 and 2004 cohorts as seen by the public healthcare system. This improvement reflects the expansion of basic healthcare, albeit still deficient, provided by SUS. Achievements in this sense are therefore unequivocal.

The c-section rate in Brazil is one of the highest in the world, accounting for about $36 \%$ of deliveries 3 . In Pelotas, c-sections increased from $27 \%$ in 1982 to $45 \%$ in 2004 . In countries with low frequencies of hospital deliveries, many mothers who effectively need c-sections do not have access to this procedure, especially those of low socioeconomic level 15. A lack of access to c-sections does not seem to be a problem in Pelotas, apart from a few isolated incidents. The greatest reason for concern is the excess number of c-sections. A recent study including 120 hospitals in Latin America showed that c-section rates show a direct association with higher maternal mortality and morbidity, as well as with higher rates of preterm birth and fetal and neonatal mortality, even after adjustment for risk factors 16 . There is also evidence that children born by c-section are more susceptible to the occurrence of asthma in early adulthood 1,17 .

The evaluation of gestational risk shows that, in spite of recent improvements, inequalities still remain. Unlike the presence and frequency of antenatal care, where lower-income mothers showed the greatest improvements, women at high gestational risk failed to show an above average gain in any of the parameters evaluated. This suggests that the changes observed are due 
mostly to the general expansion of the healthcare network than to specific investments in improving the care provided to high-risk women.

Unlike in other cities 11,12, 2004 coverage rates for the Sabin and triple vaccines in Pelotas were equal to, or even lower than, those of 1993. This finding is paradoxical, given that, in addition to the absence of shortages in vaccine supplies over the period, there was an increase in the primary healthcare network, which facilitated the access of families to healthcare services. A possible explanation for this finding is that, having reached high levels of coverage already in the early 1990s, immunization was no longer a priority among local healthcare facilities, leading to decreases in these rates in subsequent years.

The increase in the primary healthcare network in Pelotas allowed a greater number of pregnant women access to antenatal care and to physician-assisted delivery, especially among the poor. The same was true for infant care. This may be attributed to a marked increase in the supply of care to the poorest population: the primary network was expanded, and coverage became virtually universal with the implementation of the SUS system. Less marked increases among high-income mothers and children can mostly be explained by the fact that coverage levels were already satisfactory in 1982, showing that benefits tend to initially reach the wealthier strata 18 . In qualitative terms, however, it is much more difficult to decrease inequality, given that this would depend on improvements in the performance of healthcare professionals, as well as on the active search for high-risk mothers and children.

\section{Resumo}

Este estudo teve como objetivo descrever os indicadores de atenção à saúde durante o pré-natal, parto e primeiro ano de vida em Pelotas, Rio Grande do Sul. Em 1982, 1993, e 2004, todas as crianças que nasceram em hospitais na área urbana de Pelotas foram incluídas num estudo de coorte. Durante o período, o número de mulheres que não receberam atendimento pré-natal diminuiu de 4,9\% para 1,9\%; o número médio de consultas de pré-natal aumentou de 6,7 para 8,1; a proporção de gestantes que iniciaram o pré-natal no terceiro trimestre da gravidez diminuiu de $14,8 \%$ para 7\%; a taxa de cesarianas aumentou de $27,7 \%$ para $45,2 \%$ e a proporção de partos assistidos por médicos aumentou de $61,2 \%$ para $89,2 \%$. No primeiro ano de vida, as taxas de imunização melhoraram principalmente entre 1982 e 1993, enquanto o número de consultas médicas preventivas melhorou na coorte de 2004. Esse aumento de cobertura foi maior entre mães e crianças de baixa renda, o que pode refletir a implementação de cobertura universal no Brasil; entretanto, em 1982 a cobertura já era alta para mães e crianças de renda mais alta, reduzindo assim os espaço para ganhos adicionais nessa faixa de renda.

Saúde Materno-Infantil; Serviços de Saúde; Estudos de Coortes

\section{Contributors}

J. A. Cesar was responsible for data analysis and drawing up the first draft of the article. A. Matijasevich and I. S. Santos provided support in the data analysis and in writing. A. J. D. Barros, F. C. Barros and C. G. Victora defined the study scope and contributed with the revision of later versions. J. S. Dias-da-Costa helped with revising the final version of the article. 


\section{References}

1. Victora CG. Intervenções para reduzir a mortalidade infantil, pré-escolar e materna no Brasil. Rev Bras Epidemiol 2001; 4:3-69.

2. World Health Organization/United Nations Population Fund/United Nations Children's Fund/World Bank Statement. Reduction of maternal mortality. Geneva: World Health Organization; 1999.

3. Bem-Estar Familiar no Brasil. Pesquisa nacional sobre demografia e saúde 1996. Rio de Janeiro: Bem-Estar Familiar no Brasil/Macro International; 1997.

4. Cesar JA. Community health workers in Sergipe, Brazil: implications for their future role in maternal and Child health [Masters Thesis]. London: London School of Hygiene and Tropical Medicine; 2005.

5. Barros FC, Vaughan JP, Victora CG, Huttly SRA. An epidemic of caesarean sections in Brazil? The influence of tubal ligations and socioeconomic status. Lancet 1991; 338:167-9.

6. Núcleo de Informações em Saúde. Coeficiente de mortalidade infantil e ocorrência de óbitos maternos por município. Porto Alegre: Secretaria de Estado da Saúde do Rio Grande do Sul; 2005.

7. Barros AJD, Santos IS, Matijasevich A, Araújo CL, Gigante DP, Menezes AMB, et al. Methods used in the 1982, 1993, and 2004 birth cohort studies from Pelotas, Rio Grande do Sul State, Brazil, and a description of the socioeconomic conditions of participants' families. Cad Saúde Pública 2008; 24 Suppl 3:S371-80.

8. Chamberlain R, Phillip E, Howlett B, Claireaux A. British births 1970. v. 2: obstetric care. London: Heinemann; 1970.

9. Barros FC, Victora CG, Vaughan JP, Capellari MM. Perinatal risk in Third World cities. World Health Forum 1985; 6:322-4

10. Kirkwood B. Essentials of medical statistics. London: Blackwell Scientific Publications; 1988.
11. Cesar JA, Mendoza-Sassi R, Horta BL, Ribeiro PRP, D'Avila AC, Santos FM, et al. Indicadores básicos de saúde infantil em área urbana no extremo sul do Brasil: estimando prevalências e avaliando diferenciais. J Pediatr (Rio J) 2006; 82:437-44.

12. Monteiro CA, França Junior I, Conde WL. Evolução da assistência materno-infantil na cidade de São Paulo (1984-1996). Rev Saúde Pública 2000; 34:19-25.

13. Costa JS, Facchini LA. Utilização de serviços ambulatoriais em Pelotas: onde a população consulta e com que freqüência. Rev Saúde Pública 1997; 31:360-9.

14. Dias-da-Costa JS, Victora CG, Barros FC, Halpern R, Horta BL, Manzolli P. Assistência médica materno-infantil em duas coortes de base populacional no Sul do Brasil: tendências e diferenciais. Cad Saúde Pública 1996; 12 Suppl 1:S59-66.

15. Ronsmans C, Holtz S, Stanton C. Socioeconomic differentials in caesarean rates in developing countries: a retrospective analysis. Lancet 2006; 368:1516-23.

16. Villar J, Valladares E, Wojdyla D, Zavaleta N, Carroli G, Velazco A, et al. Caesarean delivery rates and pregnancy outcomes: the 2005 WHO global survey on maternal and perinatal health in Latin America. Lancet 2006; 367:1819-29.

17. Costa Lima R, Victora CG, Menezes AM, Barros FC. Do risk factors for childhood infections and malnutrition protect against asthma? A study of Brazilian male adolescents. Am J Public Health 2003; 93:1858-64.

18. Victora CG, Vaughan JP, Barros FC, Silva AC, Tomasi E. Explaining trends in inequities: evidence from Brazilian child health studies. Lancet 2000; 356:1093-8.

Submitted on 29/Mar/2007

Final version resubmitted on $07 /$ Nov/2007

Approved on 10/Jan/2008 